\section{Case Reports in Dermatology}

\title{
Carcinoma Cuniculatum of the Right Thenar Region with Bone Involvement and Lymph Node Metastases
}

\author{
Robert Feldmann Marlies Wruhs Tobias Peinhaupt Alexander Stella \\ Friedrich Breier Andreas Steiner \\ Department of Dermatology, Municipal Hospital Hietzing, Vienna, Austria
}

\section{Keywords}

Carcinoma $\cdot$ Epithelioma cuniculatum $\cdot$ Hand $\cdot$ Metastases

\begin{abstract}
Squamous cell carcinoma (SCC) is the second most common type of skin cancer after basal cell carcinoma (BCC). The overall prevalence of BCC is 3 times higher than that of SCC, but this can vary when looking at specific locations such as the hand, where SCC is much more common than BCC. Carcinoma (or epithelioma) cuniculatum is a rare variant of SCC. It was originally described as a verrucous carcinoma of the soles. Exceptionally, it can arise in other parts of the skin. We report a rare case of carcinoma cuniculatum of the right thenar region with bone and lymph node involvement.

(C) 2017 The Author(s) Published by S. Karger AG, Basel
\end{abstract}

\section{Introduction}

Squamous cell carcinoma (SCC) is the second most common type of skin cancer after basal cell carcinoma (BCC). The overall prevalence of BCC is 3 times higher than that of SCC, but this can vary when looking at specific locations such as the hand, where SCC is much more common than BCC. 
Carcinoma (or epithelioma) cuniculatum is a rare variant of SCC. It was originally described as a verrucous carcinoma of the soles. Exceptionally, it can arise in other parts of the skin. We report a rare case of carcinoma cuniculatum of the right thenar region with bone and lymph node involvement.

\section{Case Report}

An 85-year-old female patient presented with a 1-year history of a slow-growing lesion in the right thenar region. According to the patient, the lesion had developed after a minor injury with a cactus spine. Aside from diabetes mellitus type 2 and arterial hypertension, her medical history was unremarkable.

Skin examination revealed an ill-defined slightly erythematous large exophytic tumour with multiple superficial ulcerations in the right thenar region (Fig. 1a, b). The lesion spread to the dorsal aspect of the right hand and was pressure sensitive. The remainder of the skin examination was unremarkable.

Histological examination showed acanthotic epidermis with hyperkeratosis and parakeratosis (Fig. 2). The epithelial cells were well differentiated without mitotic activity, having a deceptively benign appearance. The rete pegs extended into the deep reticular dermis and keratin-filled cysts were found within the tumour mass. Pan-cytokeratin staining was positive and highlighted the extensive infiltration of the tumour into the dermis (Fig. 3). Immunohistochemical staining for p53, indicating TP53 gene mutation, was positive. In addition, immunohistochemistry was positive for cytokeratin $5 / 6$ and nucleus positivity of p63 and p40 antibodies. Immunohistochemistry for papillomaviruses (high- and low-risk human papillomaviruses [HPV]) was negative.

In the synopsis of clinical appearance of the tumour as well as histological and immunohistochemical examination, a diagnosis of carcinoma cuniculatum was established. Concerning the aetiology, the patient denied exposure to radiation or having had common warts (except in childhood).

The MRI of the right hand showed that the tumour measured 5-3 cm and infiltrated the thenar muscle and the tendon sheats. The X-ray also revealed osteolytic lesions of the first metacarpal and the trapezoid bone (Fig. 4). Metastatic involvement of the homolateral axillary lymph nodes was diagnosed by ultrasound and CT scan. ${ }^{18 F-F D G ~ P E T / C T ~ s c a n ~ s h o w e d ~}$ multiple osseous (axis skeleton) and lymph node metastasis.

With regard to the extension of the tumour and in accordance with the patient, chemotherapy or treatment with anti-PD-1 antibodies was not applied. Following the decision of a multidisciplinary tumour board a palliative radiotherapy was performed.

\section{Discussion}

SCC is the second most common skin cancer after BCC. Its incidence has strongly increased over the last decades. The main aetiological factor is sun exposure in combination with a person's individual susceptibility, i.e. skin type [1]. Accordingly, there are considerable regional and ethnical differences in SCC incidence rates. Other aetiological factors are infection with HPV, immunosuppression, chronic inflammation, and exposure to radiation or certain chemicals, such as arsenic [1-3]. 
Carcinoma cuniculatum is a rare variant of SCC, first described in 1954 by Aird et al. [4] on the foot. It is a low-grade verrucous carcinoma with a deceptive aspect of normal cell maturation. It has an endophytic burrowing growth pattern. The name "cuniculatum" derives from the appearance of the network of epithelial strands resembling a rabbit warren [4]. The tumour is characterized clinically by an exophytic verruciform appearance and may become ulcerated [5].

Aside from the feet, carcinoma cuniculatum has been described on the hands, fingers, buttock, penis, knees, and mucous membranes (oral and nasal cavity, larynx, pharynx, oesophagus) [6, 7]. The aetiological factor of carcinoma cuniculatum is unknown, but it can develop in areas of chronic inflammation. HPV has been associated with this tumour, specifically HPV 11 and 16 in plantar lesions. In our patient, the search for papillomaviruses was negative. The lesion seemed to have developed after minor injury with a cactus spine, which does not appear to be causal.

Carcinoma cuniculatum is a slow-growing tumour with local malignancy and only rare extension to lymph nodes. However, our case highlights the need for diagnostic imaging techniques to evaluate local and systemic propagation. Surgery is the first-line treatment. In inoperable or metastatic cases radiotherapy is recommended $[8,9]$. Immunotherapy with ipilimumab or anti-PD-1 antibodies, such as nivolumab and pembrolizumab, may be used in the future [10].

\section{Statement of Ethics}

The patient's informed consent was obtained.

\section{Disclosure Statement}

The authors have no conflict of interest to disclose.

\section{References}

1 Bonerandi J, Beauvillain C, Caquant L, et al: Guidelines for the diagnosis and treatment of cutaneous squamous cell carcinoma and precursor lesions. J Eur Acad Dermatol Venereol 2011;25(suppl 5):1-51.

2 Schmults CD, Karia PS, Carter JB, et al: Factors predictive of recurrence and death from cutaneous squamous cell carcinoma: a 10-year, single-institution cohort study. JAMA Dermatol 2013;149:541547.

3 Subramaniam P, Olsen CM, Thompson BS, et al: Anatomical distributions of basal cell carcinoma and squamous cell carcinoma in a population-based study in Queensland, Australia. JAMA Dermatol 2017;153:175-182.

4 Aird I, Johnson HD, Lennox B, et al: Epithelioma cuniculatum: a variety of squamous carcinoma peculiar to the foot. Br J Surg 1954;42:245-250.

5 Wastiaux H, Dreno B: Recurrent cuniculatum squamous cell carcinoma of the fingers and virus. J Eur Acad Dermatol Venereol 2008;22:627-628.

6 Maciburko SJ, Townley WA, Hollowood K, et al: Skin cancers of the hand: a series of 541 malignancies. Plast Reconstr Surg 2012;129:1329-1336.

7 Schiavon M, Mazzoleni F, Chiarelli A, et al: Squamous cell carcinoma of the hand: fifty-five case reports. J Hand Surg 1988;13:401-404.

8 Cheo $\mathrm{T}$, Ng I, Ooi KH, et al: Long-term remission after low dose radiotherapy in patient with extensive squamous cell carcinoma of the hand: a case report. Medicine (Baltimore) 2016;95:e5013.

9 Fu T, Aasi SZ, Hollmig ST: Management of high-risk squamous cell carcinoma of the skin. Curr Treat Options Oncol 2016;17:34. 


\section{Case Reports in Dermatology}

\begin{tabular}{l|l}
\hline Case Rep Dermatol \\
\begin{tabular}{l|l}
\hline DOI: 10.1159/000484038 & $\begin{array}{l}\text { C } 2017 \text { The Author(s). Published by S. Karger AG, Basel } \\
\text { www.karger.com/cde }\end{array}$ \\
\hline
\end{tabular}
\end{tabular}

Feldmann et al.: Carcinoma Cuniculatum of the Right Thenar Region with Bone Involvement and Lymph Node Metastases

Day F, Kumar M, Fenton L, et al: Durable response of metastatic squamous cell carcinoma of the skin to ipilimumab immunotherapy. J Immunother 2017;40:36-38.
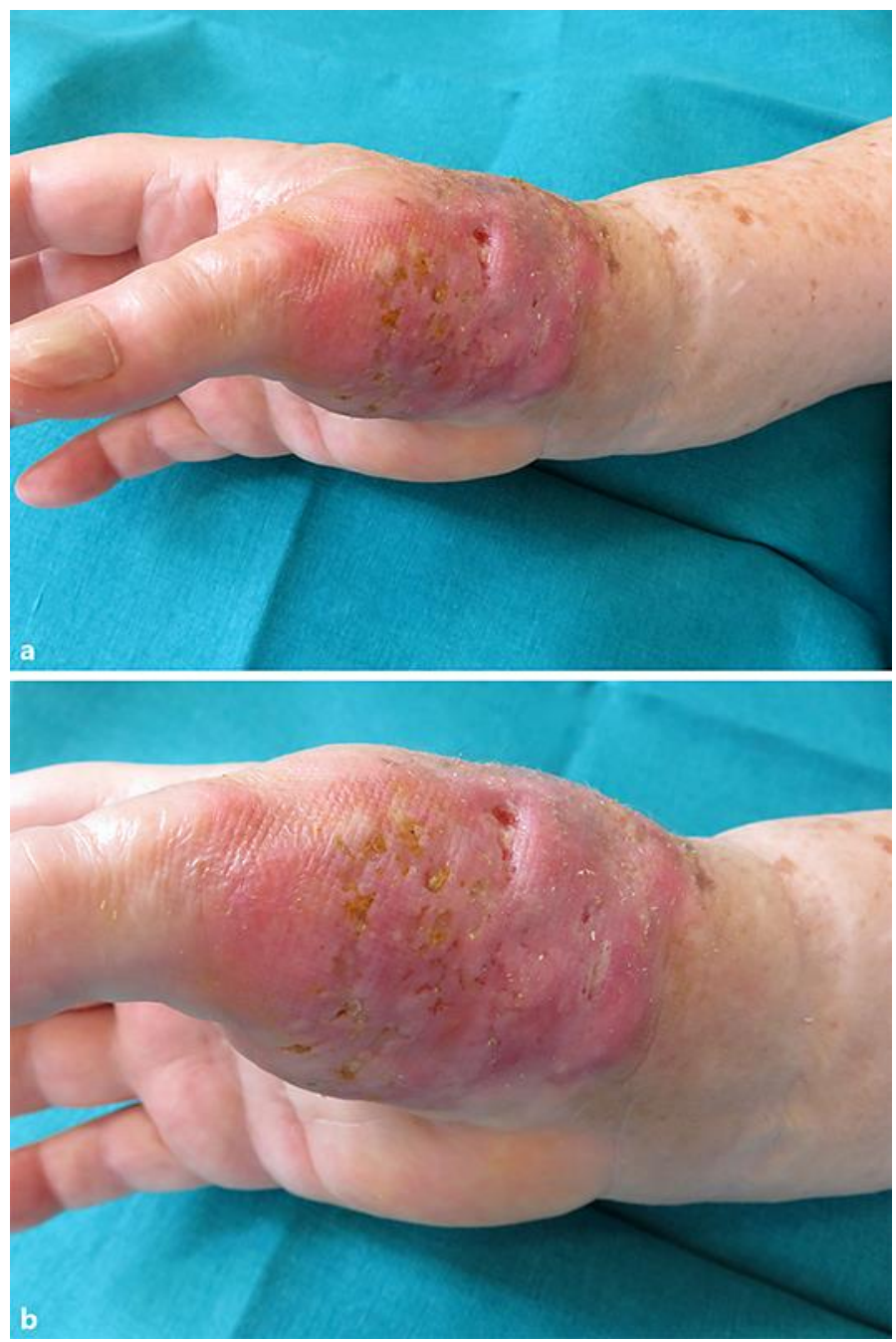

Fig. 1. a, b Large exophytic ulcerated tumour in the right thenar region. 


\section{Case Reports in Dermatology}

\begin{tabular}{l|l}
\hline Case Rep Dermatol \\
\hline DOI: 10.1159/000484038 & $\begin{array}{l}\text { c } 2017 \text { The Author(s). Published by S. Karger AG, Basel } \\
\text { www.karger.com/cde }\end{array}$ \\
\hline
\end{tabular}

Feldmann et al: Carcinoma Cuniculatum of the Right Thenar Region with Bone Involvement and Lymph Node Metastases

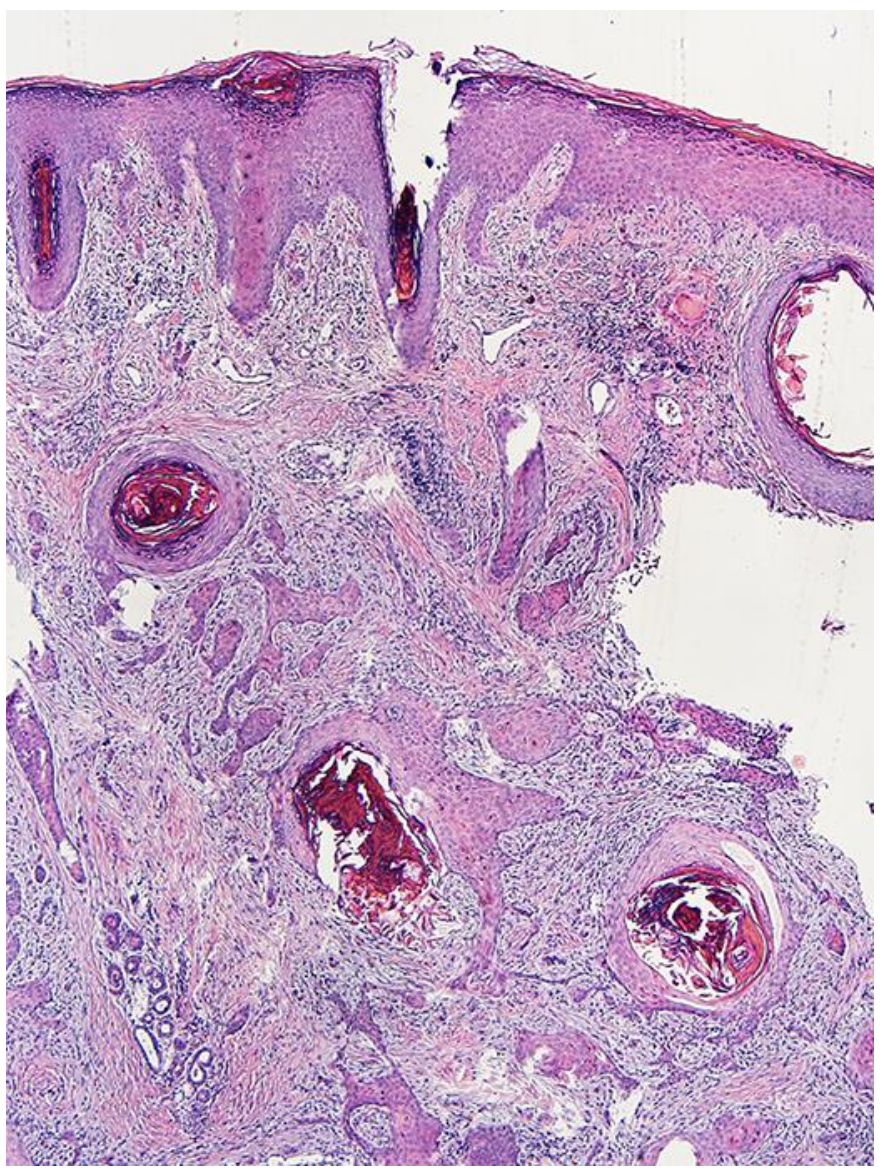

Fig. 2. Histology. HE staining. $\times 100$. Well-differentiated epithelial proliferations into the deep reticular dermis with keratin-filled cysts.

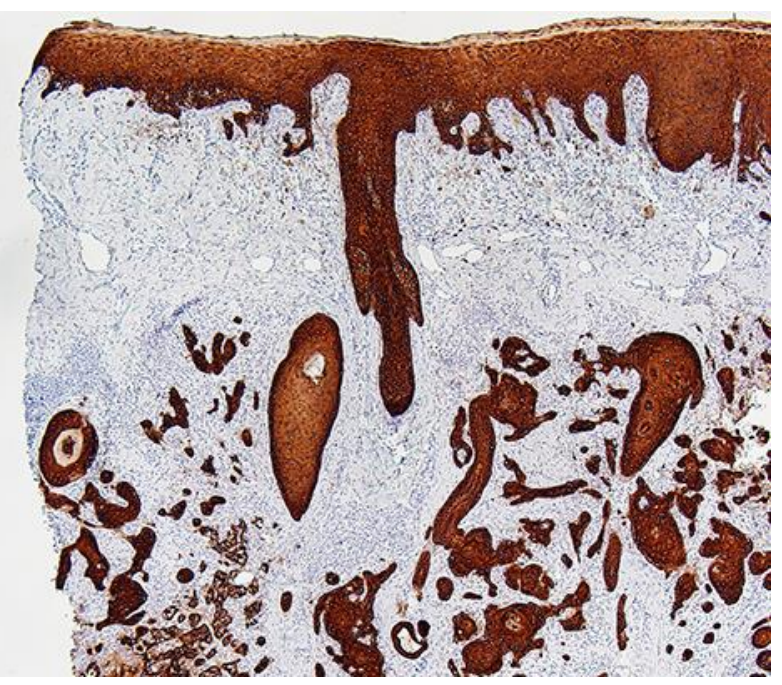

Fig. 3. Pan-cytokeratin staining. $\times 200$. Extensive infiltration of tumour into the dermis. 


\section{Case Reports in Dermatology}

Case Rep Dermatol
DOI: $10.1159 / 000484038$

(c) 2017 The Author(s). Published by S. Karger AG, Basel www.karger.com/cde

Feldmann et al.: Carcinoma Cuniculatum of the Right Thenar Region with Bone Involvement and Lymph Node Metastases

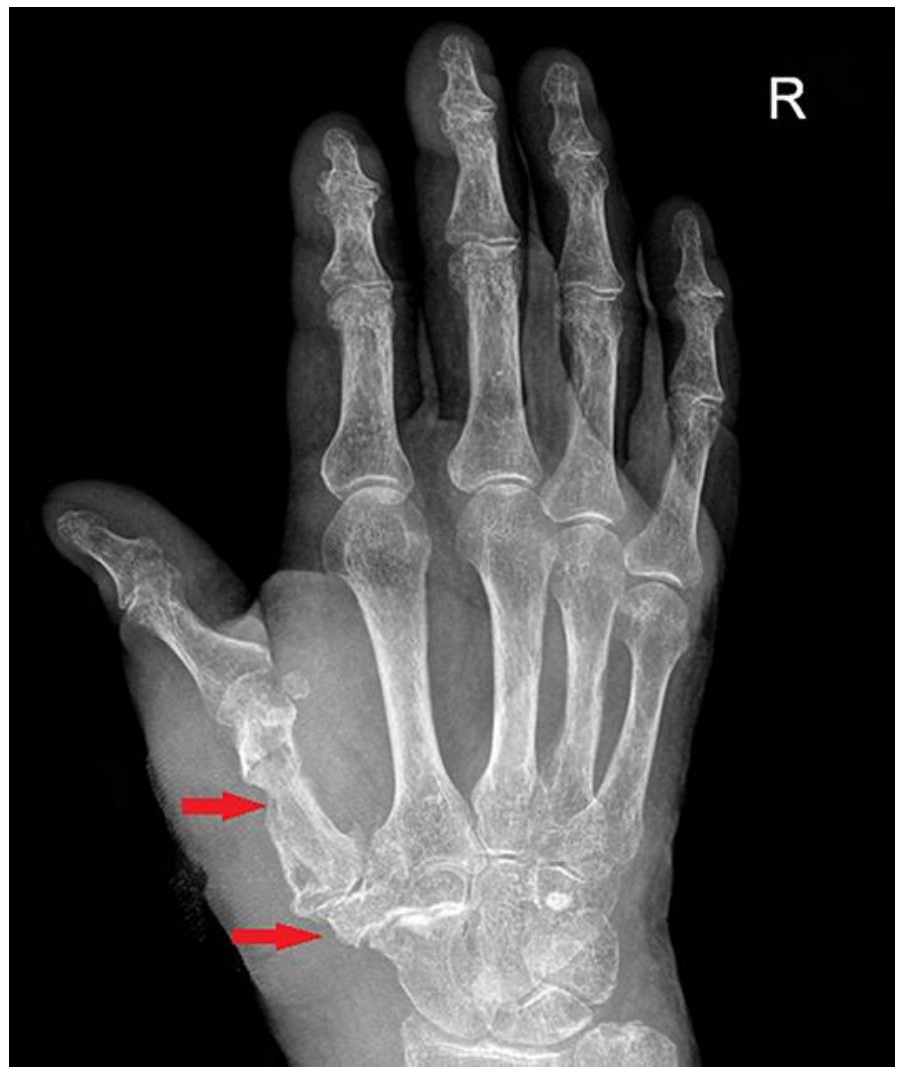

Fig. 4. X-ray of the right hand: osteolysis of the first metacarpal and trapezoid bone (arrows). 